\title{
20 ANOS DO GRUPO VOZES DA EDUCAÇÃO: MEMÓRIAS DE UMA HISTÓRIA CONSTRUÍDA COLETIVAMENTE - ENTREVISTA REALIZADA COM UMA DE SUAS FUNDADORAS, PROFESSORA MARIA TEREZA GOUDARD TAVARES
}

\author{
Elaine Ferreira Rezende de Oliveira ${ }^{\mathrm{i}}$ \\ Faculdade de Formação de Professores UERJ \\ oliveiraelaine1@gmail.com
}

\begin{abstract}
Resumo
Entrevista realizada com a professora Maria Tereza Goudard Tavares, uma das fundadoras do Núcleo de Pesquisa e Extensão Vozes da Educação: Memória, História e Formação de Professores, o primeiro da Faculdade de Formação de Professores da UERJ. O objetivo foi apresentar um levantamento memorialístico da produção do grupo ao longo dos seus vinte anos. A leitura de sua produção pode oferecer compreensão sobre formas e meios em que a escolarização e a formação de professores estão sendo reconstituídos historicamente nas últimas décadas na cidade de São Gonçalo. Desde 1996, o Grupo Vozes busca produzir pesquisa educacional ligada à realidade regional, dando atenção especial à realidade das redes públicas de ensino e aos espaços não formais de educação nos diferentes municípios do estado.
\end{abstract}

Palavras chave: Grupo Vozes da Educação, Memória, História e Formação de Professores.

\section{YEARS OF THE VOICES OF EDUCATION GROUP: MEMOIRS OF A HISTORY BUILT COLLECTIVELY - INTERVIEW FULFILLED WITH ONE OF ITS FOUNDERS, TEACHER MARIA TEREZA GOUDARD TAVARES}

\begin{abstract}
Interview with Professor Maria Tereza Goudard Tavares, one of the founders of the Núcleo de Pesquisa e Extensão Vozes da Educação: Memória, História e Formação de Professores, the first of the Faculdade de Formação de Professores da UERJ. The objective aimed to present a memorialistic survey of the group's production along its twenty years. The reading of its production can offer understanding about ways and means in which the education and teachers training are being historically reconstructed in recent decades in São Gonçalo city. Since 1996 , the Group Voices seeks to produce educational research linked to the regional reality, with special attention to the reality of public schools and non- formal spaces of education in various cities of the state.
\end{abstract}

Keywords: Voices of Educacion Group, Memory, History and Formacion of Teachers. 


\section{ANOS DO GRUPO VOZES DA EDUCAÇÃO: MEMÓRIAS DE UMA HISTÓRIA CONSTRUÍDA COLETIVAMENTE - ENTREVISTA REALIZADA COM UMA DE SUAS FUNDADORAS, PROFESSORA MARIA TEREZA GOUDARD TAVARES.}

Quais os objetivos e contribuições do Grupo Vozes da Educação para a Formação de Professores/as em São Gonçalo nos seus vinte anos de existência? Qual o legado da produção e atuação de suas pesquisadoras e pesquisadores para a Faculdade de Formação de Professores da UERJ? Como o Grupo Vozes pensa e atua sobre a formação de professores e professoras no único campus de uma Universidade Pública na segunda maior cidade do estado do Rio de Janeiro?

Essas e outras questões nortearam a elaboração de uma entrevista realizada por mim com a professora Maria Tereza Goudard Tavares, uma das fundadoras do Núcleo de Pesquisa e Extensão Vozes da Educação: Memória, História e Formação de Professoresii, que funciona na Faculdade de Formação de Professores da Universidade do Estado do Rio de Janeiro FFP/UERJ e é carinhosamente chamado pelos seus membros de Grupo Vozes.

Cabe aqui ressaltar que em 1996, além da professora Maria Tereza Goudard Tavares, foram fundadoras do Grupo Vozes as professoras Martha Hess, que se encontra aposentada desde 2005, e a professora Haydée Figuêiredo, falecida precocemente no ano de 2003.

Tentarei nessa introdução resgatar minha trajetória acadêmica que possui estreita relação com o Grupo Vozes, para justificar o cruzamento da minha trajetória com esse importante núcleo de pesquisa em história e memória da educação do município de São Gonçalo.

Minha Licenciatura em História foi cursada na Faculdade de Formação de Professores da UERJ entre os anos de 1998 a 2001. Retornei a essa instituição no ano de 2005, quando terminei o mestrado e trabalhei durante um ano, como professora substituta do Departamento de Educação, na Faculdade em que iniciei minha trajetória na Docência e Formação de Professores. No meu retorno como docente da FFP, tive os primeiros contatos com as ações desenvolvidas pelo Grupo Vozes pelas professoras Maria Tereza Goudard e Martha Hess.

Foi uma honra e uma responsabilidade muito grande lecionar na Universidade em que tinha feito minha graduação, ao lado de professores e professoras que muito contribuíram para a minha formação. Destaco, entre elas, Maria Tereza Goudard Tavares que participou ativamente da minha formação, desde o início da minha graduação até a participação na banca de conclusão do meu doutoramento em Educação na Universidade Federal Fluminense, concluído no ano de 2010.

Em 2009, voltei a lecionar na Faculdade de Formação de Professores da UERJ, 
ministrando disciplinas nos cursos de Licenciatura em História e Pedagogia. Nesse período, ingressei como pesquisadora no Grupo Vozes.

Nessa perspectiva, declaro aqui minha alegria por realizar uma entrevista com Maria Tereza Goudard Tavares, acerca das memórias e histórias do Grupo Vozes para uma edição especial da Revista Artes de Educar, que tem como objetivo comemorar os 20 anos de existência do Grupo Vozes, cujos pesquisadores e pesquisadoras me acolheram nas suas atividades de ensino, pesquisa e extensão desde o início da minha carreira como professora universitária.

Desse modo, essa entrevista buscará apresentar um levantamento memorialístico da produção do grupo Vozes ao longo dos seus vinte anos de existência, assim como rememorar as principais ações do primeiro núcleo de pesquisa e extensão criado na Faculdade de Formação de Professores - FFP da UERJ, no município de São Gonçalo.

O Grupo Vozes desde sua fundação tinha o objetivo de dar vez e voz aos educadores que atuavam nas escolas de educação básica no município de São Gonçalo. Para Martha Hess, o objetivo da fundação do Vozes era "a criação de núcleos de memórias nas escolas de São Gonçalo, e a reconstrução da historiografia da educação local” (HESS, mimeo, p.3).

Segundo suas fundadoras, a ideia de criação do Vozes surgiu a partir de uma viagem realizada pela professora Martha Hess ao Rio Grande do Sul, onde participou de um evento em que assistiu a apresentação de um grupo que pesquisava a memória e a história das professoras e professores de uma cidade daquele estado. A partir daí, foi organizada uma Gincana Cultural na Faculdade de Formação de Professores da UERJ em São Gonçalo, com o objetivo de coletar dados e materiais que possibilitassem a criação de um núcleo de memória, história e formação de professores na cidade.

A ideia da gincana reuniu em torno de um objetivo Martha Hess, Haydée Figueirêdo e Maria Tereza Goudard Tavares. O nome Vozes foi sugerido por Maria Tereza, pois esperava-se que o grupo ouvisse, pesquisasse e produzisse conhecimento acerca dos/as professores/as das escolas da cidade em que a FFP foi criada.

Segundo o projeto de pesquisa que criou o Grupo Vozes, ele se constituía naquele momento como:

Uma proposta do Departamento de Educação, considerada como uma iniciativa estratégica que pretende atingir aos seguintes objetivos: criação de um núcleo de memória e história das escolas na FFP, com vistas a preservar aspectos históricos das instituições escolares do município, garantindo o registro do passado, possibilitando aqueles que o consultarem o retorno às origens, buscando no passado o saber necessário para superar as dificuldades do presente. Reconstrução dos acontecimentos do passado através de diferentes fontes como: arquivo, 
fotos, testemunhos verbais, cartas, etc, revivendo a história social e política da escola a partir de suas raízes, visando a compreensão da dimensão sócio-histórica do processo educacional escolarizado em São Gonçalo. Através do núcleo, pretendemos estreitar vínculos entre a FFP e demais instituições educativas do município, encaminhando atividades de extensão e pesquisa. (NÚCLEO DE PESQUISA E EXTENSÃO VOzES DA EDUCAÇÃO: MEMÓRIA HISTÓRIA E FORMAÇÃO DE PROFESSORES, 1996, mimeo).

Desse modo, nesta entrevista busco levantar, conhecer e historicizar a produção do Grupo Vozes, cuja leitura pode oferecer condições de compreensão sobre formas e meios em que a escolarização e a formação de professores estão sendo reconstituídos historicamente nas últimas décadas na cidade de São Gonçalo.

Para construir o roteiro dessa entrevista foram consultados os primeiros projetos de pesquisa escritos pelas fundadoras do Grupo Vozes, artigos e livros produzidos pelos/as pesquisadores/as do grupo e o acervo do núcleo na FFP.

Cabe considerar que, desde sua criação no ano de 1996, o Grupo Vozes busca produzir pesquisa educacional ligada à realidade regional. Portanto, desde os primeiros trabalhos, foi dada uma atenção especial à realidade das redes públicas de ensino e aos espaços não formais de educação do estado do Rio de Janeiro e seus diferentes municípios.

Nas palavras de Haydée Figueirêdo, uma das fundadoras do Grupo Vozes: "podemos até dizer que estamos inaugurando uma linha de pesquisa de história regional dentro do Departamento de Educação”. (FIGUEIRÊDO, 2010).

A seguir apresento a entrevista realizada com a professora Maria Tereza Goudard Tavares, acerca das memórias e histórias do Grupo Vozes, durante os seus vinte anos de existência. Essa professora, pesquisadora e educadora vivenciou as primeiras ações do Grupo Vozes desde sua fundação. Do relato que transcrevo na íntegra, podemos concluir que muito já foi e tem sido feito para a preservação da história, memória e formação de professores na cidade de São Gonçalo.

\section{1-Como foi sua trajetória profissional e experiência de chegada no Grupo Vozes da} Educação, na Faculdade de Formação de Professores da UERJ?

A minha entrada na Faculdade de Formação de Professores ocorreu em novembro de 1995, a partir do $1^{\circ}$ concurso do Departamento de Educação. A minha posse se deu em março de 1996, o que me possibilitou o exercício da profissão docente no Ensino Superior. A entrada na Faculdade de Formação de Professores me propiciou o encontro com as professoras do DEDU Martha Hees e Haydée Figueiredo. Com elas iniciei a minha formação de professora 


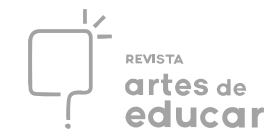

universitária, embora a FFP nessa conjuntura não pudesse ser considerada uma instituição de ensino superior, no sentido "Stricto Sensu" do termo. Ela parecia uma escola, por causa de sua pouca inserção na Pesquisa e na Extensão. A preocupação com a pesquisa no Departamento de Educação, e a sua relação com as escolas do município contribui para que em novembro de 1996, nós três criássemos o Núcleo de Pesquisa e Extensão Vozes da Educação: Memória e História das Escolas de São Gonçalo, que se constituiu como o primeiro grupo de Pesquisa e Extensão cadastrado do Departamento de Educação na UERJ. As primeiras Vozes a compor o núcleo foram as das professoras Haydée Figueiredo (1950-2003), Marta Hees e a minha. A preocupação com o "desenho" do Núcleo Vozes da Educação, o Núcleo Vozes, como carinhosamente o chamávamos, nos possibilitou muitos encontros, conversas, estudos, um tempo de intensidades e aprendizagens mútuas, tempo de (auto)formação, no qual eu aprendi muito com as queridas Haydée e Martha, "professoras Sherazades”, inspiradoras de horizontes em meu trabalho docente na FFP.

Do ponto de vista teórico-metodológico, a preocupação em dar uma sustentação mais acadêmica ao Núcleo Vozes nos levou a fundamentar nossas reflexões no campo historiográfico conhecido como Nova História, particularmente, a partir do que Burke (1992) denomina História do acontecimento e nos conceitos de polifonia e dialogismo de Mikhail Bakhtin (1992). Nesse sentido, objetivávamos constituir o Núcleo Vozes da Educação vinculando-o ao movimento das escolas e dos professores(as) do município de São Gonçalo. O Vozes já nasceu com uma preocupação dialógica! A questão da memória e da história das escolas, dos processos escolares, dos sujeitos escolares era um campo muito atraente para Martha e para Haydée, muito mais do que para mim, que vinha de uma tradição de pesquisas no campo da alfabetização das crianças das classes populares, oriunda do Grupalfa, da Universidade Federal Fluminense, UFF.

Porém, segundo Barthes (2003), o discurso da memória é, fundamentalmente, um discurso amoroso. Concordando com esse autor, posso hoje afirmar que a minha vinculação inicial com o Vozes da Educação nutriu-se de um forte investimento afetivo e um igualmente vigoroso compromisso político-epistêmico com o desafio de planejar e implementar ações indissociadas de ensino, pesquisa e extensão. Dessa forma, ainda que muito brevemente, me dediquei fortemente a organizar o Núcleo Vozes, a ler e a estudar a história local, a estudar, com Martha e a Haydée, dispositivos de estruturar institucionalmente ( para dentro e para fora da FFP e da UERJ) e materialmente o Núcleo Vozes da Educação.

Desse modo, falar sobre o processo de quase duas décadas vivido no interior do Vozes, interrogando e refletindo sobre as suas práticas e movimentos, implica entre tantas questões, em voltar no tempo, lavar os olhos, olhar para trás. Buscar reconstruir, pacientemente, na memória 
as fartas lembranças (embora muitas vezes difusas e fragmentadas) de uma história viva e pulsante, uma história que nos instiga a contá-la.

Nesse sentido, do ponto de vista metodológico, entendo a cartografia como possibilidade de uma análise compreensiva visto que esse método (DELEUZE e GUATTARI, 1996) me permite acompanhar os diferentes processos de trabalho do Vozes em sua historicidade, buscando tensionar a minha implicação como pesquisadora que se percebe implicada naquilo que (d)escreve. E que assume a impossibilidade da produção do conhecimento, apartando o sujeito que conhece (pesquisa) daquilo que é conhecido. Nesse sentido, ainda acho epistemicamente valioso o texto que escrevi em 2008 (Percursos e Movimentos: Dez anos do Vozes da Educação em São Gonçalo), no qual procurei cartografar os movimentos do Vozes, em três grandes linhas; linhas estas, que em nosso percurso, se conectam, se transversalizam, se conflituam e que nos convidam, na atualidade, a (re)inventá-las. A metáfora da linha nos remete às artes do tecer, aos fios e tramas, às mulheres-memórias, às professoras Sherazades, que como Martha e Haydée (In memória), cotidianamente contribuem para que as crianças, jovens e adultos construam os "fios de suas meadas", na escola e na vida. Tínhamos naquele momento a clareza política e institucional da importância da criação de um grupo de pesquisa com as características do Vozes. Assim, o tempo fundador do Vozes foi o do encontro entre as possibilidades latentes e oportunidade preexistentes ou criadas (Santos, 1997). Seu espaço, enquanto territorialidade foi a Faculdade de Formação de Professores e a cidade de São Gonçalo. Suas motivações, o desejo de conhecer, de reconstruir a memória e a História da Educação escolar gonçalense, de criar interfaces com as escolas e com os diferentes sujeitos escolares.

Nosso desejo de parcerias com as escolas da cidade, sempre se nutriu da compreensão de que a dinâmica espaço-temporal das práticas educacionais presentes no município de São Gonçalo requeria uma leitura atenta do seu passado. Percebíamos que nos lançando nas rugosidades do passado, inquirindo-o, tornava-se possível compreender com mais radicalidade o presente. O presente, não como um lugar estável resultante de um passado igualmente único e estável, que se descobre e se recupera. Por isso, ancorávamos na concepção de um passado plural, que não pode ser reduzido a uma única forma e conteúdo. O passado como um território movediço, marcado pelos vários passados reconstruídos pelo trabalho interessado de quem o pesquisa.

Partilhávamos, as três professoras do grupo original de uma compreensão coletiva, que foi um princípio nucleador do Vozes: a construção do saber histórico, do conhecimento da memória e da história da educação escolar gonçalense, como qualquer outro processo de construção de conhecimento, é um trabalho minucioso, lento, inacabado, que se constrói a partir 
da produção de verdades parciais, utilizando-se de categorias instáveis, conceitos provisórios e de muita pesquisa empírica (HARDING, 1993).

No estudo da História de Educação no liame das continuidades e rupturas que os processos educacionais apresentam, “ a contribuição da história para o enfrentamento dos problemas educacionais contemporâneos é justamente afirmar que escolhas foram feitas e, diante delas que futuros foram apagados" (NUNES, 2004).

Assim, a constituição do Vozes privilegiou ao ouvir as "vozes do passado" não uma postura saudosista, de retorno àquelas experiências do passado, no sentido de recolhê-las, revivêlas, mas na compreensão atenta das pistas e indícios que as mesmas nos ofereciam. E o primeiro dispositivo de ação e interlocução do Vozes com a comunidade acadêmica, e com as escolas da cidade foi a gincana "Sua memória vale uma história", realizada na FFP, em novembro de 1996, com o objetivo de dar materialidade ao núcleo (nesse momento já cadastrado e nomeado junto aos setores institucionais da universidade) e construir o seu acervo inicial. Inicialmente pensado como dispositivo para a gincana de lançamento do Vozes na FFP, em 1996, o "mote" "Sua memória vale uma historia" tornou-se um método no sentido de uma ferramenta de diálogo com as escolas da cidade, como um "Cartão de Visita" do Núcleo Vozes. A gincana "Sua memória vale uma história", idealizada pelas professoras (especialmente, por Martha Hees, tendo como parâmetro o modelo de criação de um museu escolar no sul do Brasil), constituída de dez tarefas que envolviam levantamento de fontes documentais e iconográficas da História da Educação local, não teve grandes repercussões no cotidiano da FFP. Na verdade, houve pouca divulgação por parte dos professores do Vozes, além de um certo “estranhamento" por parte da comunidade acadêmica, o que acarretou que somente três equipes, compostas exclusivamente por alunos dos cursos de História, Letras e Pedagogia fossem formadas. O acontecimento das equipes serem exclusivamente formadas por estudantes, sem a participação de professores e servidores técnicos-administrativos, provocou-nos certa frustração, visto que a gincana visava intencionalmente, construir adesões a um projeto de memória institucional, que a longo prazo, se materializasse na criação do Centro de Memória da Faculdade de Formação de Professores.

Segundo Haydée Figueirêdo, em artigo apresentado em 1998 (e publicado posteriormente em 1999) no I Encontro Anual de Iniciação Científica da Universidade Salgado de Oliveira (UNIVERSO), a gincana objetivava dar visibilidade ao Vozes, além de "construir um primeiro acervo documental que nos permitisse investigar o passado da Educação gonçalense" (1999, p.105). No desenvolvimento da gincana, coletamos uma razoável e promissora documentação, que foi posteriormente catalogada nas seguintes séries: I) Provas Escolares; II) Propostas governamentais; III) Programas escolares; IV) Orientações pedagógicas V) Contra-cheques de 


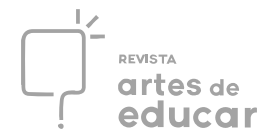

profissionais da escola; VI) Concursos de remoção; VII) Fotografias; VIII) Festa escolares; IX) Documentos Sindicais, X) Diplomas; XI) Materiais de alfabetização XII) Livros sobre a história de São Gonçalo e XIII) Matérias de jornais sobre a Educação gonçalense. Ainda sobre a Gincana "Sua memória vale uma história", a equipe vencedora, por ser um grupo de estudantes de História, conseguiu coletar e organizar um rico acervo documental sobre a educação gonçalense. Essa documentação tornou-se nosso primeiro acervo de fontes para o estudo e a investigação da História da Educação local.

E foi justamente a riqueza, a pluralidade, a polifonia dessas primeiras fontes que contribuíram para (re)afirmar o compromisso de nossas vozes com a história da educação local, com os processos educacionais que no presente pareciam ser atravessados pelas marcas do passado.

\section{2-Como a convivência com Haydée Figueirêdo marcou sua atuação como educadora, professora e pesquisadora?}

É fundamental ressaltar a centralidade da professora Haydée Figueirêdo, a nossa "intelectual local" em meu processo formativo. Haydée era muito estudiosa, gostava de ir com radicalidade aos problemas estudados. Gostava da teoria e da fundamentação conceitual que atravessava as questões de história e memória no campo educativo. A partir de 1997, novas vozes se associaram ao grupo, que nesse momento já contava com uma estudante do curso de história como bolsista de extensão, e certa visibilidade na Faculdade de Formação de Professores. Do ponto de vista teórico-metodológico e da própria estruturação das ações institucionais do Vozes, afirmávamos nesse momento, com maior pregnância e adesão, aos nossos princípios de trabalho: a indissociabilidade entre ensino, pesquisa e extensão e a relação dialógica com o "mundo da escola". Vivíamos em um intenso movimento de produção de ideias, de agenciamentos solidários e gestação de projetos. Nesse contexto, os subprojetos Profissãoprofessor(a) e Video-educador(a), desenvolvidos internamente na FFP, e abertos tanto à comunidade acadêmica, quanto à comunidade externa, já procuravam afirmar as categoriaschave do trabalho de produção do conhecimento do Vozes: memória, história e formação de professores.

O projeto Profissão-professor(a), pensado e realizado em parceria com o Sindicato Estadual dos Profissionais da Educação SEPE/S.G oportunizou que professores/as com vasta experiências no campo da docência, pudessem dialogar com estudantes das diferentes licenciaturas da FFP (Pedagogia, História, Geografia, Biologia, Letras e Matemática), e com professores(as) da rede municipal e estadual de São Gonçalo. Já o subprojeto Vídeo-educador(a), 
ancorando na exposição e debates de vídeos, de curta-metragem sobre grandes educadores brasileiros, gerou como produto um boletim-síntese de pelo menos dois vídeos apresentados. $\mathrm{O}$ diálogo com o SEPE/SG e a presença constante de professores (algumas inclusive, alunas de nossas licenciaturas) da rede pública, em nossos eventos, corroborou para a abertura de espaços, aproximações e parcerias com as escolas da cidade. De uma forma lenta e gradual, o Grupo Vozes passou a ser convidado para participar de eventos (semanas pedagógicas, palestras, mesas redondas, etc) nas escolas da rede municipal e estadual de São Gonçalo.

Paralelo a esse movimento de interfaces com as escolas da cidade, procurávamos também ampliar nossos diálogos com os grupos de pesquisa, que tanto no Rio de Janeiro, como em todo o país, tinham a memória, a história e a formação de professores como temas de suas preocupações e propostas de investigações $O$ tema da história da educação local passou a ser objeto de estudo e reflexão sistemática dos professores e bolsistas (Letras e História) do Vozes. Buscávamos em nossos encontros semanais, embora, muitas vezes atropeladas pelas rotinas e burocracia institucional, estudar autores, como Le Goff, Pierre Nora, Paul Thompson, Benjamin, Jacques Revel, Clarice Nunes, Denice Catani e Zélia Fabri Demartine, dentre outros.

O exercício afetivo de retorno ao passado me possibilita nesse momento, quase vinte anos depois, reconstruir com saudade as fortes lembranças das inúmeras vezes em que nos reunimos entre livros, textos, conversas (a)fiadas na sala 305, onde tecíamos entre café e biscoitos, feitos artesanalmente por Martha Hees, as bases dialógicas e polifônicas do Vozes. É vital ressaltar a centralidade de Haydèe Figueiredo, a nossa "intelectual local", em nosso trabalho (auto) formativo. Pois, segundo essa professora, o tema de educação em São Gonçalo, suas tensões e perspectivas, era sempre um convite à reflexão.

Aprendi muito com a professora Haydée, sobretudo sobre a importância das fontes históricas no estudo dos fenômenos educativos. Creio que aprendemos juntas, estudando de forma coletiva, que o caminho teórico-metodológico mais apropriado, face à complexidade do crescente processo de municipalização da educação escolar brasileira, reflexo da nova lógica da descentralização do Estado e suas políticas públicas, era identificar e problematizar as interfaces onde se conectavam o local, o nacional e o mundial, tentando compreender as especificidades, as complementariedades, as rupturas que as políticas educacionais e suas tendências se revestiam no plano local. Percebíamos nesse contexto que a trajetória de construção do pensamento educacional brasileiro sinalizava a possibilidade de afirmação de um pensamento históricocrítico, que nos permitia pensar o papel dos processos educacionais locais no bojo dos sistemas educacionais nacionais e internacionais. Delimitamos, portando, nosso enfoque investigativo no corpus conceitual que se convencionou chamar de história local. Ou seja, entendemos com base 
em Revel (1998) que a mudança da escala de observação pode gerar outro efeito de conhecimento quando focalizamos as histórias particulares procurando (re)conhecê-las enquanto uma modalidade particular, um recorte de uma determinada história.

Desse modo, ao alçarmos o local como categoria central de compreensão e análise, buscávamos construir outra densidade no contexto das interdependências entre agentes e fatores constitutivos dos processos e experiências históricas específicas, como no caso da educação gonçalense.

Compreendemos então, que ao darmos centralidade à categoria local, estávamos definindo, com base em Revel (1998, p.14), que pode-se afirmar que nenhuma escala tem privilégio sobe outra, já que é o seu cotejo que traz o maior benefício analítico.

Nesse sentido, não se tratava, em nosso trabalho de pesquisa, de opor o local ao global, mas sim compreender que o que a experiência de um indivíduo, de um grupo, de um espaço permite compreender é uma modulação particular do global. Investigar a história local implica, ainda segundo Revel, uma versão diferente da história global. Neste sentido os microhistoriadores participam de maneira próxima ou distante, de processos e, portanto, se inscrevem em contextos de dimensões e de níveis variáveis, do mais local ao mais global. O princípio da variação da escala estabelece que a escolha de uma escala particular de observação produz efeito de conhecimento. A partir dessa compreensão, em nossas pesquisas, buscamos tomar como paradigma os pressupostos teórico-metodológicos propostos por Revel.

A proposição entende que o "encolhimento do campo de observação" transforma-se num princípio epistemológico. Isso pressupõe a redefinição dos pressupostos de análise sóciohistórico, da noção de estratégia social, da noção de contexto. Assim, a partir do comportamento dos indivíduos reconstroem-se as modalidades de agregação (ou desagregação) social. Ou seja, a microanálise substitui os sistemas classificatórios baseados em critérios explícitos, pela decisão de levar em consideração os comportamentos por meio dos quais as identidades coletivas se constituem e se deformam. Levando em conta em suas análises uma pluralidade de destinos particulares, os micro-analistas procuram reconstituir um espaço de possíveis - em função dos recursos próprios de cada indivíduo ou de cada grupo no interior de uma configuração dada. Assim, quando localizamos os nossos estudos no município de São Gonçalo, nos defrontamos com um conjunto de relações que excedem os limites físicos do território. Encontrávamo-nos diante de teias de relações, que faziam do local um espaço multidimensional, estendido não apenas nas fronteiras visíveis do espaço, mas no conjunto de práticas sociais que se dinamizam e atravessam os vários níveis da ação humana. 


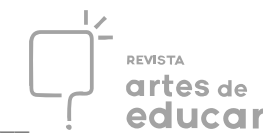

Aprendi com Haydée que, ao estudar a educação local procurando inventariar o seu passado, é possível rever relações entre passado e presente, problematizando-as. A reconstituição do passado reavivado pelas tintas do presente nos possibilita compreender, por exemplo, a interdição do direito à educação pública na cidade; compreender, por exemplo, como em determinadas conjunturas históricas, os poderes locais se tornavam mais, ou menos vulneráveis às pressões sociais pela democratização quantitativa e qualitativa da escola no município.

Nessa relação com as escolas da cidade, fomos investindo no diálogo universidade-escola básica, tendo em vista o desafio de estender ((ex)tender) o conhecimento produzido dentro da universidade e, ao mesmo tempo, trazer à universidade o conhecimento produzido no cotidiano escolar, uma vez que reconhecemos a escola como espaço-tempo de produção /atualização de uma teoria em movimento 2 que é necessário ser (re)conhecida e apropriada pelas professoras, pelos sujeitos escolares.

Através do procedimento metodológico (a gincana "sua memória vale uma história") iniciamos a construção de núcleos de memórias em escolas da rede tendo, nesse primeiro momento como único critério de definição, o desejo de investigação-cúmplice da escola. Objetivávamos com a implantação dos núcleos de memória reconstruir, através de narrativas e da análise documental, a história das escolas municipais de São Gonçalo, envolvendo os sujeitos escolares nesse movimento, a partir do entrelaçamento das memórias individuais e coletivas, da história social e política, da história da educação e da instituição escolar. Desse modo, buscávamos:

- possibilitar espaços narrativos envolvendo professores(as), funcionários(as) e alunos(as), para relato das histórias de vida, dos movimentos individuais e coletivos, indicando tramas entre formação, saberes e práticas e a mediação desse processo com a produção da escola a ser pesquisada;

- realizar levantamento e análise documental da memória da instituição escolar e da educação em São Gonçalo, através dos arquivos da escola pesquisada e da Secretaria Municipal de Educação;

- trabalhar com depoimentos orais: realização de entrevista com um grupo delimitado de professores(as), alunos(as), funcionários(as) que atuam na instituição e com a comunidade; realização de entrevistas com sujeitos que atuaram e estudaram na instituição em períodos anteriores.

Esse movimento, inicialmente muito tímido, de implantação de núcleos de memória nas escolas da rede, nos proporcionou um período muito fértil de discussões teóricas e metodológicas, especialmente, sobre a questão da história oral. Pois, no processo da escola de contar a própria história observávamos que memórias, lembranças, acontecimentos submersos e 


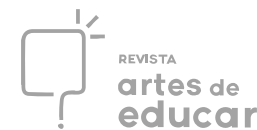

até mesmo experiências concretas, viessem à tona, saíssem das zonas de sombra disputando espaço com a História Oficial. E o meu enamoramento pela História da Educação, com certeza, deve-se ao bom encontro com Haydée Figueirêdo e a sua grande paixão por esse campo de estudo e produção de conhecimento.

\section{3- E Como a produção do Voes contribuiu para a Formação de professores e professoras no único campus de uma Universidade Pública, localizado na cidade de São Gonçalo?}

O processo de criação e consolidação do Vozes da Educação foi muito pedagógico, ocorrendo progressivamente, ao longo da consolidação da própria FFP, com entrada de mais professoras e professores a partir de concursos públicos realizados para docentes no Departamento de Educação. Uma das professoras, inclusive, com formação em história e muita experiência no trabalho com fontes e documentos em história da Educação, fortaleceu epistemicamente, o trabalho de pesquisa do Vozes e suas interfaces com a História da Educação, tendo a história local, a história oral como campo de diálogo e aprofundamento.

Esse momento caracterizou-se por uma vasta produção do Vozes: cursos, artigos, parcerias, apresentação de trabalhos, organização de seminários etc. A entrada de mais três professoras para o núcleo, inspirou desafios maiores, culminando na organização de um curso de extensão interdepartamental, a organização de um livro derivado do curso e a realização do I Seminário de Educação - "Paulo Freire na contemporaneidade" em 2001, com a presença de mais de 600 participantes, sendo o primeiro evento da Faculdade de Formação de Professores a obter financiamento de uma agência de fomento - a FAPERJ.

Em minha escuta sensível (BARBIER, 1994) sempre buscamos no interior do Vozes uma vontade de potência, entendendo que a complexidade inerente ao trabalho na/da Universidade ora podia potencializar, ora podia dificultar as nossas ações de ensino, pesquisa e extensão. Creio que as relações de afeto, respeito e confiança, (re)afirmadas em nossas trajetórias pessoais e profissionais, sempre contribuíram para que mesmo em momentos de muita tensão, agravadas especialmente pela deterioração do trabalho docente e do crescente sucateamento da universidade/escola pública, nossas vozes se fortalecessem e buscassem construir, mesmo em condições adversas, respostas criativas e solidárias aos riscos de silenciamento de si.

A dimensão do encontro (DELEUZE, 1996) sempre alimentou nossas vozes, nos desafiando a continuar nossos percursos, caminhando, lançando-nos à aventura do caminho. 
4- A partir de uma reflexão acerca do tempo presente, que mensagem você gostaria de deixar registrada para aqueles e aquelas que pretendem se tornar educadores e educadoras?

Creio que a mensagem principal é a própria trajetória, o percurso de constituição do Vozes da Educação. Buscando coerência com nosso percurso, após a realização do $\mathrm{I}^{\mathrm{o}}$ Seminário, procuramos, enquanto núcleo, nos dedicar à criação de núcleos de memória nas escolas. Nesse momento, apesar de algumas de nós estarmos envolvidas com seus processos de doutoramento, buscávamos dar continuidade às nossas metas, aprofundando o diálogo com as escolas da cidade. A decisão de criação de núcleos das escolas mais antigas, para as mais recentes, fez com que nos aproximássemos da Escola Municipal Raul Veiga, a primeira escola pública de São Gonçalo, criada em 1937. Essa escola é emblemática do esforço coletivo e sistemático do Vozes na implantação de núcleos de memória. Em nosso trabalho de criação dos núcleos de memória nas escolas, entrávamos em contato com a escassez e dispersão das fontes e principalmente, com o descaso frente aos diferentes documentos da escola. A imagem do arquivo escolar e do próprio arquivo morto da escola com um tesouro a ser encontrado e apropriado pelo trabalho cuidadoso da pesquisadora, na maioria das vezes, era apenas uma idealização. O que encontrávamos via de regra era uma profusão de documentos misturados sem nenhum tipo de tratamento e/ou catalogação. Era como se a memória da escola teimosamente buscasse adentrar ao presente, pedindo licença para falar, porém, suas vozes muitas vezes não eram escutadas.

A falta de interesse e a necessária preservação e tratamento de acervos escolares, bem como a sua compreensão como fonte para a pesquisa em Educação, têm sido uma das questões mais nodais no trabalho do Vozes. Concordamos com Bonato (2000) sobre a importância do arquivo escolar, que pode contribuir com a pesquisa educacional e histórica da instituição e da sociedade na contemporaneidade.

Assim, o compromisso com a recuperação da informação contida nos diferentes registros documentais que compõem a memória da educação escolar gonçalense tornou-se, não só uma necessidade de reconstruir e preservar a memória institucional e cotidiana de nossas escolas, mas fundamentalmente a possibilidade de estabelecer eixos articuladores que nos permitam historicizar e problematizar as políticas públicas, os projetos e as propostas educacionais vigentes na atualidade. Acredito que a constituição e a consolidação de uma política arquivística deva ocupar uma das principais prioridades do grupo Vozes, especialmente, no que tange aos seus próprios documentos/monumentos de sua trajetória acadêmico-institucional. Paralelo a esse movimento de contato mais sistemático com as escolas, continuávamos com nossas ações extensionistas na cidade. Vale lembrar a realização da Última aula do milênio, coordenada pela 
professora Martha Hees, realizada na FFP e com a presença de vários professores de diferentes universidades fluminense. O seminário e a exposição fotográfica Olhares sobre o Manifesto dos Pioneiros da Educação Nova de 1932, coordenado pela professora Sonia Câmara, em 2002, o curso de Extensão Afro-descendência Diversidade cultural, Educação, coordenado pela professora Regina de Jesus, também em 2002, e vários outros cursos e apresentações nas edições da UERJ SEM MUROS, nas semanas de extensão, abertas à comunidade gonçalense. A partir de 2003, outros dois professores, recém chegados à FFP/ Departamento de Educação, se agregam ao Vozes, constituindo o seu núcleo base. Consolidamos também, o aspecto institucional da pesquisa no Núcleo, conseguindo cadastrá-lo junto ao CNPQ como Diretório de pesquisa. $\mathrm{O}$ fato de nos tornarmos um diretório de pesquisa, corroborou para que, em 2004, realizássemos o II Seminário de Educação: Memória(s), História(s) e Educação: Fios e desafios na Formação de professores, com o apoio financeiro-institucional da FAPERJ e do CNPQ, bem como lançássemos, neste seminário, o livro coletivo "Vozes da Educação: 500 anos de Brasil", fruto do curso de extensão interdepartamental. Fortalecemos internamente o caráter da pesquisa, realizando em 2004, o minicurso Reflexões sobre a pesquisa sociológica: o trabalho do/da pesquisador/a com relatos orais e histórias de vida, ministrado pela professora da UNICAMP Zeila de Brito Demartine. Em termos da publicação de nossas ações e diálogo com os pares no cenário acadêmico, o ENDIPE de 2004 e o COLE de 2005 inspiraram, respectivamente, painéis coletivos, que possibilitaram aos diferentes professores do Vozes apresentar o que nos unifica e o que nos singulariza em termos de produção de conhecimento. A partir de 2005, vivemos o período de consolidação do Núcleo e uma maior visibilidade dentro e fora da Universidade: todos/as os/as nossos/as professores/as são doutores/as e todos/as desenvolvem projetos de iniciação científica, além de projetos individuais cadastrados na UERJ e em sua maioria contando com a bolsa de Prociência UERJ/FAPERJ. Realizamos o III, IV e o V Seminário Vozes da Educação (2007, 2011, 2013), sempre com muita participação de professores/as estudante do Rio de janeiro e do Brasil de modo mais amplo, lançando livros coletivos e produções individuais de Professores/as do Vozes. Essa trajetória, de quase vinte anos vem refletindo um percurso solidário e intenso. Uma trajetória marcada pelo dialogismo e pela polifonia, pelo compromisso político e pela vontade de ser mais, como nos instiga Paulo Freire. Trajetória permeada também por contradições, por fragilidades e sobretudo pela fragmentação e precarização do trabalho docente na universidade brasileira atual, que dificulta, quase impede, que projetos coletivos como o do Vozes da Educação possam continuar se desenvolvendo em consonância com suas matrizes originais. O reconhecimento institucional de pesquisa materializou-se no financiamento de um projeto de infraestrutura APQ1, garantido junto à 


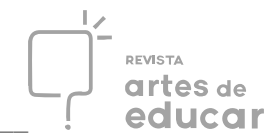

FAPERJ, que possibilitou ao Núcleo estruturar minimamente suas condições de funcionamento. A consolidação do Vozes, enquanto um respeitado núcleo de ensino, pesquisa e extensão, possibilitou também que parcerias com outras universidades e instituições fossem firmadas. A parceria com o grupo de Estudo e Pesquisas Escola, Memória e Cotidiano (GEPEMC) da Faculdade de Educação da UFF, bem como com o recém criado Centro de Memória da Educação da Baixada Fluminense, tem aberto inúmeras e férteis possibilidade de investigação cúmplice, visto que esses grupos compreendem a escola como um lócus privilegiado de (re)criação da cultura local, reafirmando o espaço da formação inicial e contínua dos professores, como um dispositivo político-epistêmico pautado nos saberes, nas memórias e nas histórias desses sujeitos. O curso de extensão (A)gente do patrimônio: oficinas de alfabetização patrimonial e formação de professores em São Gonçalo, bem como, o lançamento do Caderno da professora alfabetizadora, em 2006, em parceria com o GEPEMC/UFF, são reveladores de outro bom encontro. Desse modo, o nosso trabalho memorialístico no cotidiano da escola e na formação de professores/as tem corroborado com a perspectiva teórico-metodológico que atravessa todo o trabalho formativo do Vozes: os conceitos de memória, história, política e narração.

Assim, a(s) memória(s), a(s) história(s), a(s) política(s) e as diferentes narrativas dos diferentes sujeitos escolares nos levam à dimensão essencialmente coletiva das lembranças e dos sentidos para a trajetória dos sujeitos e das instituições escolares. É justamente nessa tensão individual/coletivo que temos nos esforçado para compreender as "vozes da escola". Narrando suas experiências, as professoras vão assumindo o papel de sujeito da história, não mais uma história contada/narrada pelo outro. Em outras palavras, os/as professor/as/es deixam de ser objetos para serem sujeitos de pesquisas, que ressignificam suas trajetórias ao longo do processo de trabalho compartilhado. A narrativa dos nossos diferentes interlocutores (professores, diretores, funcionários, estudantes, familiares etc.) faz emergir não apenas uma história individual, mas a riqueza dos significados apropriados pelo sujeito da produção social. Quem narra traz sempre os processos sociais de sua produção narrativa. Nos aproximamos assim, de um outro autor, cuja obra também alimenta as nossas produções teórico-práticas: Mikhail Bakhtin. Para esse autor, tudo que diz respeito ao sujeito chega à sua consciência por meio da palavra do outro com a sua entonação valorativa e emocional.

Ainda para Bakhtin (2003), a verdade não se encontra no interior de uma única pessoa, mas está na interação dialógica entre as pessoas que a procuram coletivamente. Portanto, a unidade de experiência e de verdade humana é sempre polifônica. Isto é, somente a tensão entre as múltiplas vozes que participam do diálogo, tanto no mundo da vida quanto no mundo da 
escola, pode dar conta da intensidade e da complexidade da realidade. Isto posto, acredito que o Vozes, desde sua gênese até os dias atuais, sempre procurou a dialogia como condição estruturante do seu fazer. Dialogia esta que procura sempre outras vozes, pois se nutre da interlocução e da contrapalavra.

O presente é para nós um tempo grávido de agoras, como nos ensina Walter Benjamin, o que nos exige compromisso com a edificação de um futuro que seja um espaço generoso e propositivo. O contexto de realização do VI Seminário de Educação Vozes da Educação - Vinte anos: Memórias, Políticas e Formação de Professores tem proporcionado um terreno fértil para (auto)reflexões, inventários e (re)avaliações. A encruzilhada político-epistêmica em que, na minha leitura interessada, nos encontramos, traduz uma complexa formulação do caminhar de nosso grupo. Vejo a encruzilhada como um lugar de trânsito, de interseção. A encruzilhada, como uma noção conceitual, nos oferece a possibilidade de cada vez mais transversalizarmos as nossas vozes, hibridizando-as, reafirmando justamente o nosso caráter polifônico e dialógico. Destaco aí, como um valor epistêmico e político justamente o caráter múltiplo e diverso de nossas pesquisas. Aí reside a nossa singularidade. Aí reside também a nossa fragilidade, visto as relações de poder presentes na constituição dos campos científicos da pesquisa. Acredito que as linhas que vêm tecendo a trajetória do Vozes, tanto internamente quanto externamente, talvez possam levar ao aprofundamento de nossos caminhos teórico-metodológicos tendo em vista o nosso desejo de re-existência, de resistência ao monologismo e ao silenciamento que ainda são hegemônicos na relação entre a universidade e a escola básica. Termino essa conversa assumindo a minha incompetência para narrar o Vozes. Assumo que o que as nossas vozes querem dizer transcende os limites dessa entrevista, enfocando os passos, o caminho e o nosso jeito de caminhar.

\section{Referências Bibliográficas:}

BARBIER, R. A Escuta Sensível em Educação. Caxambu: Revista da ANPED,1994.

BARTHES, R. Fragmentos de um discurso amoroso. São Paulo:Martins Fontes, 2003.

BAKTHIN, M. Estética da Criação verbal. São Paulo, Martins Fontes, 2003.

BURKE, P. A Escrita da História: Novas Perspectivas. São Paulo: Editora da UNESP, 1992.

BONATO.N. Memória da Educação: preservação de arquivos escolares.IN:Presença Pedagógica. Belo Horizonte: V.G.; EL. Dimensão, 2000.

DELEUZE, G. e GUATTARI, F. Mil Platôs: Capitalismo e esquizofrenia, Rio de Janeiro: Editora34, 1996.

FIGUEIRÊDO, H. Educação em São Gonçalo:Tensões e Perspectivas.IN:Vozes da Educação:500 anos de Brasil.Rio de Janeiro: Armazém das Letras , 2004.

FIGUEIRÊDO, Haydée. Vozes da Educação. In: NUNES, Clarice. (Org.). Docência e Pesquisa em Educação: na visão de Haydée Figueiredo. Rio de Janeiro: Literis Ed., 2010. 
HESS, Martha. Martha Hess, a guardiã de memórias. Texto síntese do memorial de Martha Hess, parte de sua tese de doutorado, elaborado por Maria Tereza Goudard Tavares. Faculdade de Formação de Professores da UERJ, 2005, mimeo.

HARDING, S. A Instabilidade das categorias analíticas na teoria feminista: IN:Estudos Feministas. Rio de Janeiro, V. 1.; n.1,1993.

NÚCLEO DE PESQUISA E EXTENSÃO VOzES DA EDUCAÇÃO: MEMÓRIA HISTÓRIA E FORMAÇÃO DE PROFESSORES. Projeto Vozes da Educação: Memória e história das escolas de São Gonçalo. Faculdade de Formação de Professores da UERJ, 1996, mimeo.

NUNES, C. Representações Políticas de Formação Docente no passado e no presente: questões para reflexão. IN: Anais do II Seminário de Educação,Memória(as), História(as) e Educação: Fios e Desafios na Formação de Professores. São Gonçalo:Armazém das Letras,2004.

TAVARES, Maria Tereza Goudard. Percursos e movimentos: dez anos do Vozes da Educação em São Gonçalo. In: ARAUJO, Mairce da Silva et al. Vozes da Educação: memória, história e formação de professores. Petrópolis, RJ: DP et al.; Rio de Janeiro: Faperj, 2008.

i Professora adjunta da Faculdade de Formação de Professores da Universidade do Estado do Rio de Janeiro

ii Segundo Tavares, "o Vozes foi criado em outubro de 1996, isto é, foi institucionalizado, cadastrado junto aos setores da Universidade nesse período. Porém sua gênese é anterior. Ele foi projetado em outro 'tempo lento': tempo construído nas conversas informais, reuniões departamentais, entre cafés de desejos compartilhados". (TAVARES, 2008, p. 21). 